\title{
Broadening the Patient Safety Agenda to Include Home Care Services
}

\author{
Ariella Lang, Nancy Edwards, Carolyn Hoffman, Judith Shamian, Kathleen Benjamin and Marguerite Rowe
}

\begin{abstract}
Caring for an individual in the home is inherently complex. The physical environment, family dynamics and the cognitive abilities of the client and family members are only a few of the factors to be considered in delivering services. Although targeted initiatives have been established to reduce preventable injuries and deaths in the hospital sector, there has not been a corresponding level of research or patient safety initiatives in other healthcare delivery sectors. A coordinated and collaborative approach to generate new knowledge pertaining to safety in home care in Canada has therefore been undertaken by the Canadian Patient Safety Institute (CPSI), VON Canada, and Capital Health (Edmonton). Actions included the development of a background paper (Lang and Edwards 2006) that informed an invitational roundtable discussion, where key safety issues in home care were identified and priority actions discussed. Over 40 individuals from across Canada participated, reflecting various disciplinary and organizational affiliations in the delivery of home care services. This paper describes key findings from the background paper, outcomes from the ensuing roundtable discussions and implications for practice, research and policy.
\end{abstract}

\section{Background}

There is a growing demand for home care services in Canada (Canadian Institute for Health Information 2003), and the level of patient acuity at transition to this setting is also increasing
(Canadian Institute for Health Information 2006). Caring for an individual in the home is inherently complex. The physical environment, family dynamics and the cognitive abilities of the client and family members are only a few of the factors to be considered in delivering services. Although targeted initiatives have been established to reduce preventable injuries and deaths in the hospital sector (Safer Healthcare Now 2005), there has not been a corresponding level of research or patient safety initiatives in other healthcare delivery sectors. A coordinated and collaborative approach to generate new knowledge pertaining to safety in home care in Canada has therefore been undertaken.

The Canadian Patient Safety Institute (CPSI) and VON Canada jointly identified a commitment to focus on safety in home care. Capital Health (Edmonton) was approached to collaborate, and an invitational roundtable discussion was held in conjunction with the first Patient Safety in Home, Community and Long Term Care Conference. Actions included the development of a background paper (Lang and Edwards 2006) that informed the roundtable discussion, where key safety issues in home care were identified and priority actions discussed.

Over 40 individuals, reflecting various disciplinary and organizational affiliations in the delivery of home care services, received the background paper and participated in the roundtable. This paper describes key findings from the background paper, outcomes from the ensuing roundtable discussions and implications for practice, research and policy. 


\section{Results}

The literature suggests that there has been a shift toward recognizing the complexity of the healthcare system and how it affects patient safety, while moving away from the culture of blame (Lang and Edwards 2006). Overwhelmingly, research on patient safety is focused on institutions such as hospitals. These are regulated systems designed for providing healthcare with credentialled professionals, and support staff guided by supervisors and administrators. The environment for home care is less controlled, with much of the care being provided by unregulated workers, family and caregivers in settings that were designed for daily living and not for providing healthcare (Coyte, Baranek and Daly 2000). Thus, the care and safety of patients in home care settings cannot be attended to without including the family members, the unpaid caregivers and the paid providers in the equation (Harrison and Verhoef 2002; Lehoux 2004).

Key informants from seven Canadian provinces and one American state were interviewed for the background paper. Their insightful views about issues, concerns, gaps and priorities related to safety in home care were more concordant than discordant. They shared a socioecological perspective and acknowledged that the traditional institutional patient safety perspective does not fit, but rather that a "different set of glasses" are needed to view the complexity of issues in the home setting. They discussed physical, emotional, social and functional safety. Informants recognized the importance of considering the family as the unit of care and propounded that safety for the patient is inextricably linked to the safety of family members, caregivers and providers. The implications of safety in home care need to be addressed in relationship to: service provision for vulnerable patients such as the frail elderly; ethical considerations underlying the myriad daily decisions in home care; the critical role of patients, family members and unpaid caregivers as part of the healthcare delivery team; human factors principles for technology within the built home care environment; and the cost of doing nothing, both economic and human (Lang and Edwards 2006).

Key safety issues identified at the roundtable were: the conventional institutional focus on the physical safety of the patient rather than considering the client, family, caregiver and provider as an interlinked unit; problematic communication and coordination among service sectors, providers, caregivers, family and clients; and challenges of a fit between technology and the built environment in an uncontrolled and unregulated setting such as homes.

Other important safety issues identified were medication reconciliation, wound care, fall prevention and workplace issues (e.g., regulated versus unregulated providers, casual versus part time, lack of standards). Although research on safety in home care is limited, participants agreed that there is evidence for at least some of the safety issues identified.
Key safety issues identified at the roundtable were: the conventional institutional focus on the physical safety of the patient rather than considering the client, family, caregiver and provider as an interlinked unit; problematic communication and coordination among service sectors, providers, caregivers, family and clients; ...

\section{Discussion and Implications}

Providers of home care services are guests in people's homes where the clients, family members and caregivers are active partners in their health and safety. Ignoring or minimizing the value of family members and caregivers and their respective safety is problematic. It is clear that attention to safety in the home care sector is essential. The partners in this initiative (CPSI, VON Canada and Capital Health [Edmonton]) have created the platform for further explorations of this agenda. It is important to note that by undertaking this agenda, Canada would be providing international leadership. Although there are similarities between patient safety in institutional and home care sectors, framing the research within a socioecological perspective (Edwards, Mill and Kothari 2004; Marck et al. 2006) will help us to better understand the complex interplay among determinants of safety in home care.

The roundtable is a call to action, and research is needed to support decision-making. Budget allocation to hospitals obscures the fact that most healthcare actually takes place at home and in the community. Tackling the issue of safety in the home care research agenda will require a different approach from that in institutional settings. With concentrated and collaborative efforts, a solid path may be forged.

\begin{abstract}
We've learned that there are many areas that are pertinent to home care that we do have evidence for. ... [A] strong issue came out today about the importance of family caregivers, the family as a unit. There is tons of literature on systems and intervening with the families. ... [C]ertainly, there is also enough evidence around prevention of falls, wound care and medication reconciliation that could be implemented across the country right now.

- Roundtable participant
\end{abstract}

\footnotetext{
About the Authors

Ariella Lang, RN, PhD, is a Canadian Institutes of Health Research postdoctoral fellow in the School of Nursing at the University of Ottawa. Her clinical, academic and research career has centred on improving the care to bereaved individuals and their family following the death of a loved one.
} 
Nancy Edwards, RN, PhD, holds a Canadian Health Services Research Foundation/Canadian Institutes of Health Research (CHSRF/CIHR) Nursing Chair. She is Director of the Community Health Research Unit; Principal Scientist, Institute of Population Health; Professor, School of Nursing and Department of Epidemiology and Community Medicine at the University of Ottawa; and a member of the CIHR Governing Council.

Carolyn Hoffman, RN, MN, is also Director of Operations (ON to $\mathrm{BC}$ ) at the Canadian Patient Safety Institute. Her background includes extensive experience as a critical care, emergency and home care nurse in addition to positions in clinical education, health human resources, risk management and quality improvement across various local, provincial and national roles.

Judith Shamian, $\mathrm{RN}, \mathrm{PhD}$, is president and chief executive officer of the Victorian Order of Nurses. Previously, she was the executive director, Office of Nursing Policy, Health Policy \& Communications Branch, Health Canada. Her work has focused on the areas of leadership, health system outcomes, healthy workplaces and healthy workforce issues.

Kathleen Benjamin, RN, MScN, is with the University of Ottawa and is a Research Associate with the Community Health Research Unit (CHRU). She is a recipient of a Research Fellowship from the Élisabeth Bruyère Research Institute and an Alumnae Association Bursary from the Royal Victoria Hospital Training School for Nurses, Montreal.

Marguerite Rowe is Vice-President and Chief Operating Officer, Community Care, Rehabilitation and Geriatrics Division at Capital Health in Edmonton. She is a certified Health Services Executive and an adjunct professor of Nursing at Dalhousie University.

Please direct correspondence to: Dr. Ariella Lang, 635

Powell Avenue, Mount Royal, QC H3R 1L7. E-mail:

ariella.lang@sympatico.ca.

\section{Acknowledgments}

We would like to thank the key informants for providing their informed and insightful opinions during the interview process. In addition, we extend our appreciation to Mr. Steven Lewis for his expert facilitation and good humour at the roundtable discussion as well as the participants for taking the time to share their valuable perspective. Thank you to CIHR and CHSRF for their financial support. We would also like to acknowledge and thank Mr. Philip Hassen, CEO of CPSI, for his support for this initiative. Finally, we are grateful to Ms. Orvie Coles, CPSI librarian, for her assistance with the literature search, and also her valuable editorial suggestions.

\section{References}

Amalberti, R., Y. Auroy, D. Berwick and P. Barach. 2005. "Five System Barriers to Achieving Ultrasafe Health Care." Annals of Internal Medicine 142(9): 756-64.

Baker, G.R., P.G. Norton, V. Flintoft, R. Blais, A. Brown and J. Cox. 2004. "The Canadian Adverse Events Study: The Incidence of Adverse Events among Hospital Patients in Canada." Canadian Medical Association Journal 170 (11): 1678-86. Retrieved August 10, 2006. <http://www.cmaj.ca/cgi/content/full/170/11/1678>
Canadian Institute for Health Information. 2003. Proceedings of the Home Care Summit. Retrieved August 10, 2006. <http://www.cihi.ca/ cihiweb/en/downloads/Proceedings_of_the_Home_Care_Summit_ 2003_e.pdf>

Canadian Institute for Health Information. 2006. Health Care in Canada. Retrieved August 10, 2006. <http://www.cihi.ca/cihiweb/dispPage. jsp?cw_page =download_form_e $\&$ cw_sku=06HCCPDF $\&$ cw_ $\mathrm{ctt}=1 \& \mathrm{cw} \_\mathrm{dform}=\mathrm{N}>$

Coyte, P.C., P. Baranek and T. Daly. 2000. "Identifying Outcome Indicators for Evaluating Services Provided by Community Care Access Centres (CCACs)." Report prepared under Grant 02709 from the Ministry of Health and Long-Term Care in Ontario to the University of Toronto, December. Retrieved August 10, 2006. <http://www.hcerc. utoronto.ca/PDF/short_outcomeindxccac2000.pdf>

Department of Health. 2000. An Organization with a Memory: Report of an Expert Group on Learning from Adverse Events in the NHS Chaired by the Chief Medical Officer. London: The Stationery Office. Retrieved August 10, 2006. <http://www.dh.gov.uk/assetRoot/04/08/89/48/04088948.pdf>

Downie, J., W. Lahey, D. Ford, E. Gibson, M. Thomson, T. Ward, Fiona McDonald and Alison Shea. 2006. "Patient Safety Law: From Silos to Systems." Retrieved August 10, 2006. <http://www.energyk. com/healthlaw/documents/Patient_Safety_Main_Report_final.pdf>

Edwards, N., J. Mill and A.R. Kothari. 2004. "Multiple Intervention Research Programs in Community Health.” Canadian Journal of Nursing Research 36(1): 40-54.

Forster, A.J., H.D. Clark, Alex Menard, N. Dupuis, R. Chernish and N. Chandok. 2004. "Adverse Events among Medical Patients after Discharge from Hospital." Canadian Medical Association Journal 170(3): 345-49. Retrieved August 10, 2006. <http://www.cmaj.ca/cgi/ content/full/170/3/345>

Harrison, A. and M. Verhoef. 2002. "Understanding Coordination of Care from the Consumer's Perspective in a Regional Health System." Health Services Research 37(4): 1031-54.

Institute of Medicine, K.T. Kohn, J.M. Corrigan and M.S. Donaldson. 1999. To Err Is Human: Building a Safer Health System. Washington, DC: National Academy Press.

Lang, A. and N. Edwards. 2006. "Safety in Home Care: A Background Paper for Round Table Discussion (Draft)." Retrieved August 10, 2006. <http://www.patientsafetyinstitute.ca/uploadedFiles/Research/ Safety\%20in\%20Home\%20Care\%20-\%20Apr\%202006.pdf>

Lehoux, P. 2004. "Patients' Perspectives on High-Tech Home Care: A Qualitative Inquiry into the User-Friendliness of Four Technologies." BMC Health Services Research 4(1): 28.

Marck, P.B., J.A. Kwan, B. Preville, M. Reynes, W. Morgan-Eckley and R. Versluys. 2006. "Building Safer Systems by Ecological Design: Using Restoration Science to Develop a Medication Safety Intervention." Quality and Safety in Health Care 15(2): 92-97.

Safer Healthcare Now! Campaign. 2005. Retrieved August 10, 2006. <http://www.saferhealthcarenow.ca>

Wilson, R.M., W.B. Runciman, R.W. Gibberd, B.T. Harrison, L. Newby and J.D. Hamilton. 1995. "The Quality in Australian Health Care Study.” The Medical Journal of Australia 163(9): 458-71. 